\title{
Outcome of Less Invasive Proximal Arch Replacement With Moderate Hypothermic Circulatory Arrest Followed by Aggressive Rapid Re-Warming in Emergency Surgery for Type A Acute Aortic Dissection
}

\author{
Mitsumasa Hata, MD; Mitsunori Suzuki, CE; Akira Sezai, MD; \\ Tetsuya Niino, MD; Isamu Yoshitake, MD; Satoshi Unosawa, MD; \\ Kazuma Shimura, MD; Kazutomo Minami, MD
}

\begin{abstract}
Background The mid-term outcome of quick proximal arch replacement with moderate hypothermia followed by aggressive rapid re-warming in emergency surgery for type A acute aortic dissection (AAD) was assessed. Methods and Results Eighty-five patients were divided into 2 groups: group I consisted of 43 patients undergoing surgery for deep hypothermic circulatory arrest and selective cerebral perfusion; and group II consisted of 42 patients who recently underwent aggressive rapid re-warming. During open distal anastomosis in group II patients with a rectal temperature of $28^{\circ} \mathrm{C}$ but who did not suffer any cerebral perfusion, circulating blood in the cardiopulmonary bypass (CPB) circuit was warmed to $40^{\circ} \mathrm{C}$. As soon as distal anastomosis was completed, rapid re-warming was initiated by a $40^{\circ} \mathrm{C}$ blood perfusion. The duration of CPB (I: 182.1 vs II: $85.3 \mathrm{~min}$ ), overall operation (305.0 vs $150.8 \mathrm{~min}$ ), postoperative mechanical ventilation ( $44.3 \mathrm{vs} 9.1 \mathrm{~h}$ ), and hospital stay (31.4 vs 9.6 days) were significantly shorter in group II patients. The incidence of postoperative brain complication (I: 14.0 vs II: $2.4 \%$ ), renal failure (14.0 vs $0 \%$ ), pneumonia (18.6 vs $4.8 \%$ ), and mortality (9.3 vs $0 \%$ ) was significantly less in group II patients.

Conclusions Moderate hypothermia followed by a rapid re-warming procedure was safe and effective in the proximal arch replacement for AAD. (Circ J 2009; 73: 69-72)
\end{abstract}

Key Words: Aorta; Cardiovascular diseases; Dissection

$\mathbf{S}$ urgical mortality rates during emergency operation for type A acute aortic dissection (AAD) are still estimated to range from 9 to $30 \%$, and is associated with postoperative complications such as cerebral injury, bleeding, renal failure, and pneumonia caused by longer operation time $(>6 \mathrm{~h})$, longer cardiopulmonary bypass (CPB) time ( $>4 \mathrm{~h})$, deep hypothermia, and circulatory arrest (DHA)! If surgical stress could be minimized by shortening the duration of brain ischemic stress, $\mathrm{CPB}$ and operative procedures, the surgical outcome for patients with $A A D$ could be further improved. In the majority of patients, an ascending or hemiarch replacement is sufficient, as the intimal tear is generally located in the ascending or the proximal aortic arch? Recently, it has been reported that moderate hypothermic arrest at $26-28^{\circ} \mathrm{C}$ without any adjunctive cerebral protection was safe in patients undergoing hemiarch aortic replacement? We have established a

(Received May 18, 2008; revised manuscript received August 3, 2008; accepted August 21, 2008; released online December 2, 2008)

Department of Cardiovascular Surgery, Nihon University School of Medicine, Tokyo, Japan

Mailing address: Mitsumasa Hata, MD, Department of Cardiovascular Surgery, Nihon University School of Medicine, 30-1 Ooyaguchi Kamimachi, Itabashi-ku, Tokyo 173-8610, Japan. E-mail: mihata@ med.nihon-u.ne.jp

All rights are reserved to the Japanese Circulation Society. For permissions, please e-mail: cj@j-circ.or.jp new procedure for proximal arch replacement for patients with moderate hypothermic arrest without cerebral perfusion, which is followed by aggressive rapid re-warming to shorten the duration of brain ischemia, CPB, and overall surgery. We report here on the initial results of this procedure for an octogenarian with $\mathrm{AAD}^{4}$ and have since performed this procedure for all the patients undergoing an emergency proximal arch replacement for AAD. The aim of this study is to assess the mid-term outcome of our newly modified technique.

\section{Methods}

Between March 2002 and February 2008, 114 patients underwent emergency surgery for AAD at our institution. The extent of aortic replacement was decided based on the location of the intimal tear (tear-oriented surgery). Ascending/hemiarch aortic replacement was performed in patients with the intimal tear localized in the ascending aorta or in the lesser curvature of the transverse aortic arch proximal to the left subclavian artery. In this series, 85 (74.6\%) consecutive patients underwent ascending/hemiarch aortic replacement. We retrospectively reviewed these patients. Institutional review board approval was provided before publication of this manuscript and reporting of the information. Fifty patients $(58.8 \%)$ were female, and the average age was $66.9 \pm 12.0$ years, ranging from 36 to 90 years. 
Table 1 Preoperative Morbidity

\begin{tabular}{lccc}
\hline \hline & Group I & Group II & P value \\
\hline Age (years) & $69.2 \pm 9.8$ & $64.5 \pm 13.6$ & $N S$ \\
Sex $($ M/F) & $13 / 30$ & $22 / 20$ & 0.038 \\
Occlusion type & $19(44.2 \%)$ & $21(50 \%)$ & $N S$ \\
AR & $6(14.0 \%)$ & $5(11.9 \%)$ & $N S$ \\
Tamponade & $16(37.2 \%)$ & $12(28.6 \%)$ & $N S$ \\
AMI & $3(7.0 \%)$ & $2(4.8 \%)$ & $N S$ \\
CRF & $2(4.7 \%)$ & $2(4.8 \%)$ & $N S$ \\
Cerebral infarct & $2(4.7 \%)$ & 0 & $N S$
\end{tabular}

$N S$, not significant; AR, aortic regurgitation; $A M I$, acute myocardial infarction; $C R F$, chronic renal failure.

Contrast computed tomography (CT) was performed for all patients as soon as they were referred to our hospital. Transthoracic echocardiography was then performed to detect pericardial effusion, assess aortic valve regurgitation (AR) and cardiac function. The contrast CT revealed a thrombosed occlusion type condition in 40 patients $(47.1 \%)$. Twenty-eight patients $(32.9 \%)$ were in a pre-shock state because of cardiac tamponade. Eleven patients $(12.9 \%)$ had moderate AR and 2 patients $(2.4 \%)$ had minor cerebral infarction. We divided these patients into 2 groups: group I consisted of 43 patients with deep hypothermic circulatory arrest (DHA) and antegrade selective cerebral perfusion (ACP) who underwent a standard emergency surgery during 2002 and 2005, to protect the brain; and group II consisted of 42 recent patients with moderate hypothermic circulatory arrest followed by aggressive rapid re-warming who underwent our newly developed method from January 2006. We compared the 2 groups in terms of in-hospital mortality and morbidity.

\section{Surgical Procedure for Group I}

$\mathrm{CPB}$ was implemented through femoral arterial cannulation. During the cooling phase, the temperature setting of the heat exchanger was $16^{\circ} \mathrm{C}$. Both DHA and ACP for 3 arch vessels were used for cerebral protection. Each patient was cooled to $20^{\circ} \mathrm{C}$ (rectal temperature). The ascending aorta and/or aortic arch were then opened longitudinally under DHA. The aortic segment containing the intimal tear was resected and gelatin resorcine formalin (GRF) glue was applied between the 2 dissected walls on both the distal and proximal stumps of the aorta. We used minimal amounts of glue and mixed approximately 1 part formalin to 10 parts gelatin. Furthermore, the aortic walls were reinforced by securing Teflon felt strips both inside and outside the aorta. Antegrade systemic circulation was established through a side branch of the Dacron prosthesis after completion of open distal anastomosis.

\section{Surgical Procedure for Group II}

During the cooling phase, the temperature setting of the heat exchanger was $16^{\circ} \mathrm{C}$. Circulatory arrest was implemented at a rectal temperature of $28^{\circ} \mathrm{C}$ without any cerebral perfusion. GRF glue was also used, but only the outside of the aortic walls were reinforced by Teflon felt. During open distal anastomosis, circulating blood in the CPB circuit was warmed to $40^{\circ} \mathrm{C}$ by a heat exchanger and the patient's body (with the exception of the head) was also warmed using a hyper-hypothermia system (Medi-Term II; GAYMAR Inc, Orchard Park, NY, USA). As soon as distal anastomosis was completed, antegrade systemic circulation was established through a side branch of the Dacron prosthesis and rapid re- warming was initiated by $40^{\circ} \mathrm{C}$ blood perfusion. As soon as the patient's blood was mixed first by a shot of $40^{\circ} \mathrm{C}$ blood, their drainage blood temperature increased to $30^{\circ} \mathrm{C}$ and the arterial blood decreased in temperature to $34^{\circ} \mathrm{C}$. Therefore, the temperature balance between the infusion and drainage blood was kept under $5^{\circ} \mathrm{C}$ during rapid re-warming.

In both groups, if the additional procedure of coronary bypass (CABG) was required, distal anastomosis was completed during the cooling phase, and proximal anastomosis to the Dacron graft was performed just after graft replacement during the re-warming stage.

\section{Statistical Analysis}

Results were expressed as the mean \pm standard deviation. Statistical calculations were conducted using StatView (SAS Inc, Cary, NY, USA). Using parametric and nonparametric data, statistically significant differences were determined using Student's t-test and Fisher's exact test, respectively. A P value of less than 0.05 was considered statistically significant.

\section{Results}

There was no difference between the groups in terms of average age, incidence of thrombosed occlusion, AR, cardiac tamponade, acute myocardial infarcionan, chronic renal failure, and cerebral infarction (Table 1). There were slightly more female patients in group I (Table 1). In group $\mathrm{I}$, the ascending and proximal hemiarch replacements were carried out in 29 and 14 patients, respectively. An intimal tear was resected in 38 patients, but in 5 patients, it was not identified. In group II, the ascending and proximal hemiarch replacements were carried out in 25 and 17 patients, respectively. An intimal tear was resected in 35 patients, but in 7 patients, it was not identified. Additional CABG (Saphenous vein to right coronary artery) was required for 2 patients in both groups. There was no difference in terms of operative characteristics. The rectal temperature was significantly higher in group II $\left(26.9 \pm 1.3^{\circ} \mathrm{C}\right)$ compared to group I $\left(20.4 \pm 1.1^{\circ} \mathrm{C}, \mathrm{P}<0.0001\right)$. The durations of cerebral protection (I: $63.8 \pm 13.0$ vs II: $20.6 \pm 5.1 \mathrm{~min}, \mathrm{P}<0.0001$ ), and CPB (I: $182.1 \pm 55.1$ vs II: $85.3 \pm 17.2 \mathrm{~min}, \mathrm{P}<0.0001$ ) were significantly shorter in group II. The duration of overall operation in group II was $150.8 \pm 32.6 \mathrm{~min}$, ranging from 101 to $225 \mathrm{~min}$, which was significantly shorter than that for group I $(305.0 \pm 56.4 \mathrm{~min}, \mathrm{P}<0.0001)$. The duration of postoperative mechanical ventilation in group II was $9.1 \pm 4.7 \mathrm{~h}$, which was significantly shorter than that for group I $(44.3 \pm 25.7 \mathrm{~h}, \mathrm{P}<0.0001)$. The duration of postoperative hospital stay in group II was $9.7 \pm 1.9$ days, which was significantly shorter than that for group I $(31.4 \pm 19.4$ days, 
Table 2 Operative Outcome

\begin{tabular}{lccc}
\hline \hline & Group I & Group II & P value \\
\hline Core temperature $\left({ }^{\circ} \mathrm{C}\right)$ & $20.4 \pm 1.1$ & $26.9 \pm 1.3$ & $<0.0001$ \\
Brain exclusion (min) & $63.8 \pm 13.0$ & $20.6 \pm 5.1$ & $<0.0001$ \\
CPB (min) & $182.1 \pm 55.1$ & $85.3 \pm 17.2$ & $<0.0001$ \\
OPT (min) & $305.0 \pm 56.4$ & $150.8 \pm 32.6$ & $<0.0001$ \\
Ventilation $(h)$ & $44.3 \pm 25.7$ & $9.1 \pm 4.7$ & $<0.0001$ \\
HP stay (day) & $31.4 \pm 19.4$ & $9.7 \pm 1.9$ & $<0.0001$ \\
TND & $6(14.0 \%)$ & $1(2.4 \%)$ & 0.0446 \\
Permanent brain damage & $5(11.6 \%)$ & $1(2.4 \%)$ & $N S$ \\
Re-exploration & $3(7.0 \%)$ & $3(7.1 \%)$ & $N S$ \\
ARF & $6(14.0 \%)$ & 0 & 0.0101 \\
Pneumonia & $8(18.6 \%)$ & $2(4.8 \%)$ & 0.039 \\
Tracheostomy & $5(11.6 \%)$ & 0 & 0.0196 \\
Mortality & $4(9.3 \%)$ & 0 & 0.0429 \\
\hline
\end{tabular}

$C P B$, cardiopulmonary bypass; OPT, operating time; $H P$, postoperative hospital stay; $T N D$, temporally neurological dysfunction; $N S$, not significant; $A R F$, acute renal failure.

$\mathrm{P}<0.0001$; Table 2). In group I, 6 patients experienced complications of postoperative temporally neurological disorder (TND), 5 had permanent cerebral damage, 3 were taken back to the operating theater because of bleeding, 6 required hemodialysis for postoperative renal failure, 8 had pneumonia (including 5 who required a tracheostomy), and the hospital mortality rate was $9.3 \%$ (4 patients). In contrast, just 1 or 2 patients had such complications and hospital mortality was not observed in group II. The incidence of TND $(\mathrm{P}=0.0446)$, postoperative renal failure $(\mathrm{P}=0.0101)$, pneumonia $(\mathrm{P}=0.039)$, tracheostomy $(\mathrm{P}=0.0196)$, and mortality $(\mathrm{P}=0.0429)$ was significantly less in group II than in group I (Table 2). In group I, 2 patients died because of coronary malperfusion and another 2 died in hospital because of brain damage. In group I, 6 patients died because of a traffic accident, cerebral infarction, pneumonia, heart failure, or senility during the follow-up period. In contrast, in group II, 1 patient died because of a traffic accident 6 months postoperatively, 1 patient died of cerebral bleeding 3 months postoperatively and 1 patient died because of a ruptured abdominal aortic aneurysm 7 months postoperatively. The actual survival rate at 2 and 5 years was 87.2 and $83.6 \%$, respectively in group I. It was $91.2 \%$ at 2 years follow-up for group II. There was no difference in terms of the mid-term survival rate between the groups.

\section{Discussion}

The extent of aortic replacement and operating time has been reported as significant risk factors for hospital mortality in previous reports 1.5 This is because the patients often might not be able to tolerate the aggressive surgical stress of deep hypothermia, a long duration of cerebral exclusion or CPB. Furthermore, a prolonged operation can increase mortality through coagulopathy, cerebral ischemia, infection, or multiple organ failure6 In the present study, the incidence of postoperative complications such as TND, renal failure, or respiratory failure was markedly less in those patients undergoing mild hypothermia and rapid rewarming. And there was no mortality in group II. In contrast, in group I, however, approximately $10 \%$ of the patients developed a brain injury, renal failure, or respiratory failure during deep hypothermia with ACP. And finally, 4 patients died in hospital. This might be associated with too much stress caused by DHA and a longer duration of CPB. Cook et al reported that systemic temperatures below $22^{\circ} \mathrm{C}$ might not be necessary and might be associated with a higher incidence of neurologic injury when using ACP during DHA? Greeley et al reported that those patients cooled to $28^{\circ} \mathrm{C}$ had a predicted brain ischemic tolerance of 11-19 min? Our results suggest that moderate hypothermic arrest at $28^{\circ} \mathrm{C}$ without any adjunctive cerebral protection within $20 \mathrm{~min}$ is safe. Therefore, we consider that performing surgery with the minimum invasive stress is considered to be a key factor for saving lives and maintaining of quality of life.

In the surgical intervention for $\mathrm{AAD}$, a partial or hemiarch replacement is sufficient in the majority of patients. In particular, for patients with serious dissection-related organ malperfusion, a conservative limited ascending/hemiarch replacement would be preferable. In the present study, 2 patients died because of coronary malperfusion and another 2 patients died because of brain damage in group I. In contrast, in group II, the 2 patients with coronary malperfusion survived without any mechanical support. Aortic repair and decompression of the false lumen should be performed before malperfusion causes irreversible damage to the malperfused organs. Therefore, several unique diagnosis techniques have recently been developed ${ }^{9}$ and early recognition of the disease and earlier referral to surgical units would improve the outcome of emergency surgery for this lethal disease. As the main goal of emergency surgery for acute dissection is saving the patient's life, conservative tear-oriented surgery might be appropriate. In our new technique, moderate hypothermic $\left(28^{\circ} \mathrm{C}\right)$ circulatory arrest without any cerebral perfusion for distal anastomosis was performed. Although it took approximately $20 \mathrm{~min}$ to complete the distal anastomosis, the durations for $\mathrm{CPB}$ and overall operation were approximately 85 and $150 \mathrm{~min}$, respectively, which was much quicker than those of previous reports? The shortest operation time in our study was $101 \mathrm{~min}$ from skinto-skin. In general, quicker is not always better. However, we believe that quicker surgery definitely makes for a better outcome because it can minimize the surgical stress caused by hypothermia or CPB for such a lethal disease.

In our new procedure, the patients' bodies were re-warmed quite rapidly as soon as the distal anastomosis was completed. It has been generally accepted that re-warming upon hypothermia should be conducted as slowly as possible $!^{10}$ In DHA, cerebral metabolism and oxygen extraction remain significantly reduced during re-warming and after $\mathrm{CPB}$, suggesting disordered cerebral metabolism and oxygen utilization after DHA. Furthermore, cerebral blood flow (CBF) 
significantly decreases in patients with DHA during the re-warming phase $!^{1}$ If the cerebral circulation was unable to regulate oxygen delivery after DHA, the brain would be at an increased risk of hypoxic injury during episodes of hypoxemia in the re-warming phase ${ }^{12}$ Therefore, we speculate that the potential mismatches in flow/metabolism after DHA are most likely expressed during rapid temperature or perfusion changes such as that which occurs during rewarming. In contrast, Greeley et al reported that those patients who were cooled to $28^{\circ} \mathrm{C}$ demonstrated a return to baseline in CBF during re-warming and after weaning from CPB. However, in patients exposed to DHA, cerebral reperfusion was significantly lower during re-warming and after CPB? Therefore, we believe that there is no problem to induce rapid re-warming after circulatory arrest in cases of moderate hypothermia $\left(28^{\circ} \mathrm{C}\right)$. Moreover, it can shorten the durations of $\mathrm{CPB}$ and overall operation time.

\section{Study Limitations}

This study has several limitations. It was a retrospective analysis of a study conducted at a single institution. Aggressive rapid re-warming seems to be bit eccentric as a standard approach, however, we believe that the data from this newly modified surgical technique, which can be completed in approximately $2 \mathrm{~h}$ in patients with $\mathrm{AAD}$, is quite unique. Future studies involving more patients from a variety of institutions need to be conducted in order to determine how effective this method really is.

\section{Conclusion}

Moderate hypothermia followed by an aggressive rapid re-warming procedure was safe and effective in the proximal arch replacement for AAD.

\section{References}

1. Kawahito K, Adachi H, Yamaguchi A, Ino T. Preoperative risk factors for hospital mortality in acute type A aortic dissection. Ann Thorac Surg 2001; 71: 1239-1243.

2. Ehrlich MP, Ergin MA, McCullough JN, Lansman SL, Galla JD, Griepp RB, et al. Results of immediate surgical treatment of all acute type A dissections. Circulation 2000; 102(Suppl 3): 248-252.

3. Kamiya H, Hagl C, Kropivnitskaya I, Weidermann J, Kallenbach K, Haverich A, et al. Quick proximal arch replacement with moderate hypothermic circulatory arrest. Ann Thorac Surg 2007; 83: 1055-1058.

4. Hata M, Suzuki M, Sezai A, Niino T, Yoshitake I, Minami K, et al. Less invasive quick replacement for octogenarians with Type A acute aortic dissection. J Thorac Cardiovasc Surg 2008; 136: 489-493.

5. Sabik JF, Lytle BW, Blackstone EH, McCarthy PM, Loop FD, Cosgrove DM. Long-term effectiveness of operations for ascending aoric dissections. J Thorac Cardiovasc Surg 2000; 119: 946-962.

6. Westaby S, Saito S, Katsumata T. Acute type A dissection: Conservative methods provide consistently low mortality. Ann Thorac Surg 2002; 73: 707-713.

7. Cook RC, Gao M, Macnab AJ, Fedoruk LM, Day N, Janusz MT. Aortic arch reconstruction: Safety of moderate hypothermia and antegrade cerebral perfusion during systemic circulatory arrest. $J$ Cardiovasc Surg 2006; 21: 158-164.

8. Greeley WJ, Kern FH, Ungerleider RM, Boyd III JL, Quill T, Smith LR, et al. The effect of hypothermic cardiopulmonary bypass and total circulatory arrest on cerebral metabolism in neonates, infants, and children. J Thorac Cardiovasc Surg 1991; 101: 783-794.

9. Shirakabe A, Hata N, Yokoyama S, Shinada T, Suzuki Y, Kobayashi $\mathrm{N}$. Diagnostic score to differentiate acute aortic dissection in the emergency room. Circ J 2008; 72: 986-990.

10. Rosner MJ, Rosner SD, Johnson AH. Cerebral perfusion pressure: Management protocol and clinical results. J Neurosurg 1995; 83: 949-962.

11. Croughwell ND, Frasco P, Blumenthal JA, Leone BJ, White WD, Reves JG. Warming during cardiopulmonary bypass is associated with jugular bulb desaturation. Ann Thorac Surg 1992; 53: 827-832.

12. Tsui SSL, Schultz JM, Shen I, Ungerleider RM. Postoperative hypoxemia exacerbates potential brain injury after deep hypothermic circulatory arrest. Ann Thorac Surg 2003; 78: 188-196. 